\title{
Efficacy of a National Hydrological Risk Communication Strategy: Domestic Wastewater Treatment Systems in the Republic of Ireland
}

\author{
Paul Hynds \\ Technological University Dublin, Paul.Hynds@tudublin.ie \\ Owen Naughton \\ Trinity College Dublin, Ireland \\ Eoin O'Neill \\ University College Dublin
}

See next page for additional authors

Follow this and additional works at: https://arrow.tudublin.ie/engschcivart

\section{Recommended Citation}

Hynds, P., Naughton, O. \& O'Neill, O. (2017). Efficacy of a National Hydrological Risk Communication Strategy: Domestic Wastewater Treatment Systems in the Republic of Ireland. Journal of Hydrology, no. 558, pp. 205-213. doi.org/10.1016/j.jhydrol.2018.01.041

This Article is brought to you for free and open access by the School of Civil and Structural Engineering at ARROW@TU Dublin. It has been accepted for inclusion in Articles by an authorized administrator of ARROW@TU Dublin. For more information, please contact arrow.admin@tudublin.ie, aisling.coyne@tudublin.ie, gerard.connolly@tudublin.ie.

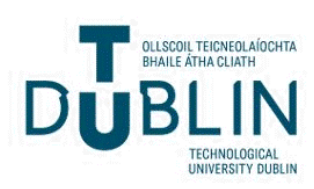


Authors

Paul Hynds, Owen Naughton, Eoin O'Neill, and Simon Mooney

This article is available at ARROW@TU Dublin: https://arrow.tudublin.ie/engschcivart/91 
Research papers

\title{
Efficacy of a national hydrological risk communication strategy: Domestic wastewater treatment systems in the Republic of Ireland
}

\author{
Paul Hynds ${ }^{\mathrm{a}, *}$, Owen Naughton ${ }^{\mathrm{b}}$, Eoin O'Neill ${ }^{\mathrm{c}, \mathrm{d}}$, Simon Mooney ${ }^{\mathrm{c}}$ \\ ${ }^{a}$ Environmental Sustainability and Health Institute, Dublin Institute of Technology, Dublin 7, Ireland \\ ${ }^{\mathrm{b}}$ Dept. of Civil, Structural and Environmental Engineering, Trinity College, Dublin 2, Ireland \\ ' UCD Planning and Environmental Policy, School of APEP, University College Dublin, Dublin 4, Ireland \\ ${ }^{\mathrm{d}}$ UCD Earth Institute, University College Dublin, Dublin 4, Ireland
}

\section{A R T I C L E I N F O}

\section{Article history:}

Received 27 May 2017

Received in revised form 6 December 2017

Accepted 17 January 2018

This manuscript was handled by G. Syme, Editor-in-Chief, with the assistance of Heather M. Smith, Associate Editor

\section{Keywords:}

Wastewater treatment

Regulation

Policy

Engagement

Socio-hydrology

Risk communication

\begin{abstract}
A B S T R A C T
A significant body of research has focused on the role of domestic wastewater treatment systems (DWWTSs) as sources of human-specific aquatic contaminants in both developed and developing regions. However, to date few studies have sought to investigate the awareness, attitudes and behaviours of DWWTS owners and the efficacy of associated communication initiatives. The current study provides an examination of a public national engagement campaign undertaken in the Republic of Ireland which seeks to minimise the impact of DWWTSs on human and ecological health via concurrent inspection and information dissemination. Overall, 1634 respondents were surveyed using a "before and after" study design to capture if and how awareness, attitudes and behaviours evolved over time. Findings suggest that whilst the campaign provided a modest baseline to raise general awareness associated with the basic operational and maintenance requirements of DWWTS, there has been little or no behavioural engagement as a result, suggesting a significant awareness-behaviour gap. Accordingly, efforts to minimise potential human and ecological impacts have been unsuccessful. Moreover, results suggest that public attitudes towards water-related regulation and policy became increasingly negative over the study period due to parallel political and economic issues, further complicating future engagement. Future strategies, both in Ireland and further afield, should focus on health-based demographically-focused message framing to achieve significant knowledge and attitudinal shifts amongst specific population cohorts, and thus bring about significant behavioural change. Study findings and recommendations may be used by myriad stakeholders including local, provincial and national authorities to effectively engage with individuals and communities prior to and during implementation of legislative and policy-based instruments within numerous spheres including climate change adaptation, environmental quality, hydrological risk, and hydro-ecology.
\end{abstract}

(c) 2018 Elsevier B.V. All rights reserved.

\section{Introduction}

Rural Ireland is currently home to approximately 37\% (1.78 million) of the national population (4.64 million), and is characterised by a heavily dispersed yet locally dense settlement pattern (Scott and Murray, 2009), with most settlements comprised of individual private or "one-off" dwellings situated outside urban administrative zones (CSO, 2012hy). An estimated one third of Irish households $(>75 \%$ of rural households) are not connected to a municipal sewerage scheme, with approximately $440,000(27.5 \%)$ individual dwellings associated with a DWWTS (CSO, 2012). When correctly located, designed, installed and maintained, DWWTSs

\footnotetext{
* Corresponding author.

E-mail address: hyndsp@tcd.ie (P. Hynds).
}

represent an appropriate method for domestic wastewater treatment and disposal. However, if improperly situated, constructed, and/or managed, they constitute a significant threat to human health and the aquatic environment via contamination of surface and groundwater resources (Hynds et al., 2012, 2014).

A significant percentage of existing DWWTSs in the Republic of Ireland are believed to be operationally deficient and situated near private wells and group water schemes, both of which are ubiquitous throughout rural Ireland (CSO, 2012; Hynds et al., 2013). When considered in concurrence with the high numbers (and density) of DWWTSs in Ireland, large areas characterised by high and extreme groundwater vulnerability, and shifting climatic patterns (i.e. increased incidence of high intensity rainfall events and flooding), the risk of groundwater contamination attributable to DWWTSs is believed to be high (Hynds et al., 2012, 2014). 
Cussen (2010) previously estimated that approximately 25,000 DWWTSs are actively polluting groundwater while approximately 120,000 are polluting surface water, with these figures likely to rise due to a marked increase in the number of "one-off" rural dwellings constructed during Ireland's property boom from the mid1990s to the mid-2000s, allied with a longstanding absence of regulatory controls pertaining to both private groundwater sources and DWWTSs (Scott and Murray, 2009; CSO, 2012). Moreover, recent studies suggest consistently increasing national rates of waterborne infection over the past decade, and note a marked association between confirmed cases and previous exposure to private wells (Garvey et al., 2016; ÓhAiseadha and Hynds, 2017).

Due to the rural infrastructural profile of the Republic of Ireland, the magnitude of these issues is almost unique, however contamination problems deriving from DWWTSs have been noted elsewhere (Borchardt et al., 2011), as have other impediments to state interventions such as geographical isolation (Castleden et al., 2015). The responsibility to safeguard ecological and human health from domestic wastewater thus frequently lies with "nonexpert" custodians (i.e. private well owners, DWWTS owners, etc.). These individuals often lack financial and/or material support, necessitating establishment of focused communication strategies to promote DWWTS risk awareness and maintenance (Castleden et al., 2015). Precedents for best practice in this field are scarce. However, existing research relating to behavioural change campaigns and public acceptance in various other domains has repeatedly emphasized the significance of contextual factors and target audience characteristics in determining campaign structure and outcomes (Howlett and Cashore, 2009; Atkin and Rice, 2012).

In late 2009, Ireland was formally admonished by the European Court of Justice (ECJ) for continued negation of its obligations to appropriately regulate domestic wastewater generated in unsewered (rural) areas, as required under articles 4 and 8 of the 1975 EU Waste Framework Directive (75/442/EEC) (European Commission, 2011). Subsequently, the European Commission announced its intention to impose a lump-sum fine ( $€ 2.7$ million) and daily penalties $(€ 26,173)$, resulting in amendments to existing national legislation and enactment of new legislation in 2012 (i.e. Water Services (Amendment) Act (WSA)). The WSA comprised a suite of obligations for DWWTS owners including system registration and appropriate maintenance/remediation, in addition to requiring local authorities to undertake DWWTS inspections within their jurisdiction. Accordingly, Ireland's Environmental Protection Agency (EPA) developed an overarching National Inspection Plan (NIP), which aimed to safeguard public health and the environment using a two-strand approach of education and awareness strategies along with a risk-based inspection process (EPA, 2013, 2015). Due to financial limitations (and perhaps, to a greater or lesser extent, a degree of political expediency), a relatively low number of inspections $(\mathrm{n} \approx 1000$ ) will be undertaken annually, thus the primary NIP component is a public information strategy to promote good practice relating to the operation and maintenance of DWWTSs (EPA, 2013).

Communication strategy structure and content were developed following consultation with various environmental, agricultural and rural interest groups, in addition to expert opinions and recommendations. Notably, there was no targeted dialogue with or platform for DWWTS householder opinions or concerns during the public consultation phase. Consequently, it was decided that the communication strategy would comprise a public awareness campaign focused on communicating key messages pertaining to clean water and appropriate DWWTS maintenance. Nationally, numerous mechanisms including national press (newspaper, radio, television) and a dedicated website were employed, with outreach activities initiated in early/mid-2013. Approximately 1.5 million information leaflets were issued to local authorities and relevant bodies (e.g. group water schemes) for distribution (EPA, 2015). Locally, employed mechanisms included: emails/letters to registered owners, information packs, leaflets, local authority website notices, local radio and newspaper articles/interviews, preinspection visits, school visits, social media notices and stakeholder meetings. (EPA, 2015).

The objective of the current study was to examine the overall efficacy of the aforementioned public risk communication campaign through comparative analyses of temporal shifts ("before and after") in awareness, perception and behaviour among DWWTS users based on a previous ("before") study undertaken prior to NIP implementation (i.e. the intervention) (Naughton and Hynds, 2014). This paper thus represents a longitudinal evaluation of a national environmental communication campaign and a timely examination of householder risk awareness and prevention pertaining to DWWTSs. More broadly, the paper examines societal responses to policy instruments and public information campaigns with respect to hydrological risks, water contamination, and human health, thus permitting assessment of strategy efficacy and development of recommendations pertaining to similar future campaigns. To guide and inform overall survey development and data collation, the following research questions were formulated:

1. What are current ("post-intervention") levels of environmental awareness and risk perception among Irish DWWTS owners and users?

2. Have levels of environmental awareness and risk perception changed over the study period?

3. Has the process of public outreach succeeded and, if not, why?

4. What amendments might be employed to improve/optimise future public hydrological communication?

\section{Materials and methods}

\subsection{Survey design and completion}

In order that direct comparisons could be made and a primary study objective realised (i.e. quantification of strategy success), several previous ("pre-intervention") survey questions associated with respondent awareness and perception (Naughton and Hynds, 2014) were retained, including all questions from Sections $1(n=10), 2(n=6)$, and $5(n=5)$, as outlined below. New questions were devised to i) investigate respondents' primary sources of information on hydrological issues in general and DWWTSs and ii) examine perceived strategy strengths and weaknesses.

Previously elucidated behavioural and/or perception-based relationships, in addition to previously highlighted knowledge gaps (Naughton and Hynds, 2014) were used to inform overall questionnaire structure, individual questions and available responses. The developed questionnaire comprised 31 questions, with dichotomous $(n=9)$, categorical $(n=12)$, and Likert-scale (ordinal) $(\mathrm{n}=8)$ response options favoured over open-ended (format) questions to ensure survey brevity, comprehension, and comparative analyses. A small scale $(\approx 5 \%$ of sample size) pilot study was undertaken for survey validation; pilot study data have been omitted from analyses. All survey questions included a "Don't Know" response option, to permit quantification of a lack of awareness or risk perception. The final questionnaire comprised five sections, as follows:

- Section 1 (10 Questions): Respondent socio demographics (age, gender, residential ownership; household size and composition; geographical location) and domestic (waste)water reliance (DWWTS type, on-site location, age, discharges and design; drinking water source and treatment) 
- Section 2 (6 Questions): DWWTS inspection and maintenance (inspection and maintenance history, knowledge of appropriate inspection and maintenance procedures including visual auditing and system desludging)

- Section 3 (5 Questions): National Inspection Plan - Public Engagement (awareness of NIP and associated public engagement, unsolicited receipt of pertinent information, perceived clarity and value of information, source(s) of information, utilised and preferred sources of information)

- Section 4 (5 Questions): DWWTS registration and remediation (system registration, likelihood/expectation of necessary remediation, perception of environmental regulation and legislation)

- Section 5 (5 Questions): Hydrological contamination (Contaminant source awareness, public health awareness, previous contamination events, perception of hydrological hazards)

The survey was initiated in November 2013, following the first round of public communication as part of the NIP, and continued over a 6-month period until April 2014, with an online recruitment and completion approach employed. The questionnaire was hosted on a cloud-based survey application and distributed among the rural Irish population via several non-professional interest groups. Respondent recruitment was initiated via distribution of an introductory email, which outlined the overall study objectives and procedure. Prospective respondents were ensured that study participation was entirely voluntary and confidential, with no potentially identifiable data collated. No financial reward was offered to participants.

Overall, 533 rural respondents completed the "post-commu nication" survey. Based upon sample size calculations employing a $95 \%$ confidence level, a conservative (50\%) "worst case" percentage, and a total DWWTS population of 450,000 households (CSO, 2012 ; EPA, 2015), the survey sample equates to a $4.2 \%$ confidence interval $(\mathrm{CI})$.

\subsection{Data analysis}

Survey responses were categorised, numerically coded and analysed using the "survey" package (Lumley, 2013) within the $\mathrm{R}$ statistical environment. Pearson chi-square tests of independence were used to determine the presence of associations between categorical (dichotomous and nominal) variable pairs. Odds ratios (OR) and associated 95\% CIs were calculated to examine the level of association between dichotomous pairs. Independent samples t-tests (difference of means with equal variance assumed) were used to test for the presence of associations between dichotomous and continuous variables (i.e. Before $=0$; After $=1$ ), with all continuous variables normalised via the Box-Cox power transformation $\left(\Lambda=-2\right.$; Transformation Eqn $\left.=1 / \mathrm{Y}^{2}\right)$. One-way analysis of variance (ANOVA) was used to test for relationships between continuous variables and categorical variables with $>2$ levels of classification (i.e. Cluster Membership 1-3). Bonferroni post hoc multiple comparison analysis was employed upon rejection of the global null hypothesis $\mathrm{H}_{0}$ (i.e. F-test with $\mathrm{p}<0.05$ ) to identify significantly different categories. The Kruskal Wallis test (one-way ANOVA on ranks) was used to examine associations between categorical variables with $>2$ levels of classification and ordinal/ranked variables. Spearman's non-parametric measure of rank correlation was used to examine relationships between continuous variables with nonlinear distributions. A p-value $<0.05$ was used by convention.

Three indicators were developed and utilised for directly comparing pre- and post-intervention respondent levels of awareness and behaviour. The "awareness performance indicator" score was calculated for each individual respondent, based upon answers to six questions which were included in both pre- and postintervention surveys, which are presented below. Scores were assigned based upon the respondent exhibiting a presence or absence of awareness, resulting in a maximum cumulative awareness score of 6 .

a. Are you aware (Yes/No) of your current domestic wastewater treatment system type? (i.e. septic tank with percolation system, soak-away, aerated system, etc.)

b. Are you aware (Yes/No) of the approximate operational age of your current domestic water supply type?

c. Are you aware (Yes/No) of the influent types currently entering your domestic treatment system? (i.e. rainwater/surface drainage, domestic greywater, domestic wastewater)

d. Have you or anyone in your household previously carried out an inspection of your domestic wastewater treatment system for operational deficiencies (Yes/No/Don't Know)?

e. Has your domestic wastewater treatment system previously been desludged (Yes/No/Don't Know)?

f. Do poorly located, constructed, or maintained domestic wastewater treatment systems constitute a potential threat to the local environment (Yes/No/Don't Know)?

Awareness performance scores were allocated as follows:

Questions a, b, c: No $=0$, Yes $=1$;

Questions d, e: Don't Know $=0$, Yes or No $=1$

Question f: No or Don't Know = 0, Yes $=1$

The "behavioural performance indicator" score (cumulative maximum: 3) was calculated based upon three analogous "before and after" questions, set out below. For the purposes of calculating "behavioural performance", respondents exhibiting an absence of awareness (i.e. Don't Know) were omitted from analyses of behavioural performance. All three questions were allocated an equal behavioural score $(\mathrm{No}=0$; Yes $=1)$

a. Have you or anyone in your household previously carried out a formal inspection of your domestic wastewater treatment system for operational deficiencies or employed an expert to do so (Yes/No)?

b. Has your domestic wastewater treatment system previously been desludged (Yes/No)?

c. Do you or anyone in your household periodically monitor your domestic wastewater treatment system for surface ponding, malodours, etc. (Yes/No)?

The "attitudinal indicator" was based upon respondent membership of one of three developed clusters. Clusters were developed based upon responses to an ordinal (ranking) question which captured respondents' attitude towards the introduction of DWWTS registration and inspection; respondents were asked to prioritise the following four rationales: environmental quality $(\mathrm{Q})$, human health $(\mathrm{H})$, governmental revenue $(\mathrm{R})$ and legislative compliance (C). Agglomerative hierarchical clustering (between groups linkage; squared Euclidean distance method) was used to optimize cluster number ("elbow" method), with k-means clustering (iteration and classification) used to assign cluster membership (Naughton and Hynds, 2014).

\section{Results}

\subsection{Respondent summary}

Overall, 533 respondents completed the post-intervention survey (Table 1). Respondents from all 26 of the Republic of Irelands administrative units (counties) were surveyed, with study findings considered geographically and demographically representative based upon the most recent (2016) Irish census. There was a signif- 
Table 1

Respondent Demographics (Gender, Age), Household Size, DWWTS and Drinking Water source associated with Pre- and Post-Intervention Survey Populations.

\begin{tabular}{|c|c|c|c|c|}
\hline \multirow[t]{2}{*}{ Variable } & \multicolumn{2}{|c|}{ Pre-Intervention (2012) } & \multicolumn{2}{|c|}{ Post-Intervention (2013/14) } \\
\hline & Frequency (\%) & Mean (SD) & Frequency (\%) & Mean (SD) \\
\hline \multicolumn{5}{|l|}{ Gender } \\
\hline Male & $786(71.4)$ & & $318(59.7)$ & \\
\hline Female & $315(28.6)$ & & $215(40.3)$ & \\
\hline \multicolumn{5}{|l|}{ Age Group } \\
\hline $18-24$ & $428(42.6)$ & & $149(28)$ & \\
\hline $25-34$ & $134(13.3)$ & & $64(12)$ & \\
\hline $35-44$ & $136(13.5)$ & & $70(13.1)$ & \\
\hline $45-54$ & $143(14.2)$ & & 89 (16.7) & \\
\hline $55-64$ & $115(11.4)$ & & $100(18.8)$ & \\
\hline $65-74$ & $47(4.7)$ & & $54(10.1)$ & \\
\hline$>74$ & $2(0.2)$ & & $7(1.3)$ & \\
\hline Household Size & & $3.99(1.95)$ & & $3.58(1.69)$ \\
\hline \multicolumn{5}{|l|}{ Domestic Wastewater System } \\
\hline Septic Tank & $460(41.6)$ & & $99(20.2)$ & \\
\hline Septic Tank + Soakaway & $176(15.9)$ & & 147 (29.9) & \\
\hline Septic Tank + Percolation & $324(29.3)$ & & $174(35.4)$ & \\
\hline Secondary System & $77(6.9)$ & & $33(6.7)$ & \\
\hline Reed/Willow Bed & $14(1.3)$ & & $8(1.6)$ & \\
\hline Don't Know & $47(4.2)$ & & $30(6.1)$ & \\
\hline \multicolumn{5}{|l|}{ Drinking Water Supply } \\
\hline Public Mains & $370(33.6)$ & & $191(35.8)$ & \\
\hline Public Group Scheme & $130(12)$ & & $47(8.8)$ & \\
\hline Private Group Scheme & $146(13.4)$ & & $95(17.8)$ & \\
\hline Private Well & $424(38.5)$ & & $172(32.3)$ & \\
\hline
\end{tabular}

icant association between respondent age and homeownership $\left(\chi^{2}(6)=330.068, \mathrm{p}<0.001\right)$, with older respondents more likely to own their current residence. Private water wells (groundwater), public mains (groundwater or surface water) and private group water schemes (primarily groundwater) accounted for $32.3 \%$ ( $\mathrm{n}=$ $172), 35.8 \%(n=191)$, and $17.8 \%(n=95)$ of respondent's domestic water supplies, respectively.

\subsection{Communication and engagement}

Just under $70 \%$ of respondents $(n=346)$ exhibited an awareness of the NIP, with differing levels of awareness associated with gen$\operatorname{der}\left(\chi^{2}(1)=5.623, p=0.018\right)$, age $\left(\chi^{2}(6)=20.787, p=0.002\right)$, and homeownership $\left(\chi^{2}(1)=4.712, \mathrm{p}=0.030\right)$. Homeowners and female respondents were 1.5 times (OR 1.540 , 95\% CI 1.0422.276 ) and 1.6 times (OR 1.626, 95\% CI 1.086-2.435) more likely than "non-homeowners" and male respondents, respectively, to exhibit an awareness of the NIP. Awareness of the NIP increased consistently with age from $62.4 \%$ among $18-24$ year olds to $86.2 \%$ among those $>55$ years. A significantly higher proportion of post-intervention respondents (79.8\%) agreed with regular DWWTS monitoring and inspection than was evident among preintervention respondents $(58.5 \%)\left(\chi^{2}(1)=54.473, \mathrm{p}<0.001\right)$.

During the 12 -month period prior to surveying, $34.9 \%$ of postintervention respondents $(n=119)$ reported having received information pertaining to DWWTS operation and maintenance during the 12-month communication period, with an equivalent figure of $29.2 \%(n=319)$ found among pre-intervention respondents (OR 1.297, 95\% CI 1.002-1.679; $\left.\chi^{2}(1)=3.917, \mathrm{p}=0.048\right)$. Within the homeowner subset, $35.2 \%(n=201)$ and $34.8 \%(n=78)$ of preand post-intervention respondents, respectively, reported having received information $(p=0.920)$, with younger (nonhomeowners) pre-intervention respondents less likely to have received information $\left(\chi^{2}(6)=21.917, \mathrm{p}=0.001\right)$. Results indicate that this imbalance no longer existed within the postintervention population sample $(\mathrm{p}=0.157)$.

In all, $27.3 \%(n=134)$ of post-intervention respondents stated that they had attempted to access information pertaining to DWWTS operation and maintenance over the communication period; homeowners were significantly more likely to have tried acquire information (OR 2.145, 95\% CI 1.379-3.338; $\chi^{2}(1)=$ $11.737, \mathrm{p}=0.001)$, with information primarily acquired via leaflets (50.45\%) and the internet (30.8\%) (Fig. 1).

Highest levels of efficacy were attributed to information sourced from the internet and information leaflets (sent to individual households by local and/or national authorities), with lowest levels associated with local radio and national newspapers (Table 2). Younger respondents were more likely associated with data acquired from the internet $\left(\chi^{2}(5)=12.266, p=0.031\right)$, local radio $\left(\chi^{2}(1)=13.559, \mathrm{p}=0.019\right)$, and social media $\left(\chi^{2}(1)=\right.$ 13.310, $\mathrm{p}=0.021)$.

Post-intervention respondents were asked to rank their media type preferences in terms of future information receipt (Table 3); male respondents exhibited a preference for national radio, newspapers, and word of mouth $(\mathrm{p}<0.05)$. Younger respondents preferred social media and word of mouth, while "traditional" media types (e.g. newspapers, radio) are preferred by older respondents (and homeowners). For example, "non-homeowners" were over four times more likely to select social media as their preferred source of information (OR 4.344, 95\% CI 2.650-7.123), and over

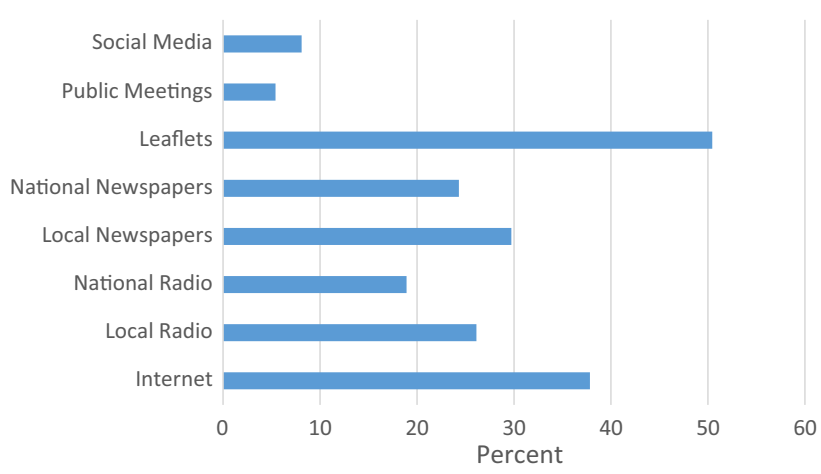

Fig. 1. Sources of relevant information during the 12-month period prior to postintervention surveying $(\mathrm{n}=134)$. 
Table 2

Reported efficacy and demographic associations with National Inspection Programme (NIP) data received from individual media outlets $(\mathrm{n}=134$ ).

\begin{tabular}{|c|c|c|c|c|}
\hline Media Outlet & Efficacy (\%) & Gender $\left(\chi^{2} \operatorname{Sig}\right)$ & Age $\left(\chi^{2}\right.$ Sig $)$ & Homeowner $\left(\chi^{2}\right.$ Sig $)$ \\
\hline Internet & 89.5 & 0.874 & 0.031 & 0.135 \\
\hline Local Radio & 62.1 & 0.852 & 0.019 & 0.006 \\
\hline National Radio & 68.4 & 0.146 & 0.487 & 0.355 \\
\hline Local Newspaper & 80 & 0.057 & 0.917 & 0.456 \\
\hline National Newspaper & 62.5 & 0.386 & 0.340 & 0.213 \\
\hline Leaflet & 87.5 & 0.456 & 0.270 & 0.385 \\
\hline Public Meeting & 83.3 & 0.043 & 0.971 & 0.528 \\
\hline Social Media & 66.7 & 0.154 & 0.021 & 0.032 \\
\hline
\end{tabular}

Table 3

Media type preferences with respect to future information acquisition and likely personal usage among post-intervention respondents $(\mathrm{n}=423$ ).

\begin{tabular}{|c|c|c|c|c|}
\hline & Mean Rank* (Std. Dev.) & Gender (KW Sig) & Age (KW Sig) & Homeowner (KW Sig) \\
\hline Internet & $3.43(1.58)$ & 0.458 & 0.456 & 0.993 \\
\hline Local Radio & $3.07(1.47)$ & 0.416 & 0.079 & 0.316 \\
\hline National Radio & $3.39(1.41)$ & 0.045 & 0.002 & 0.001 \\
\hline Local Newspaper & $3.32(1.38)$ & 0.003 & 0.019 & 0.454 \\
\hline National Newspaper & $3.29(1.34)$ & 0.006 & 0.207 & 0.394 \\
\hline Leaflets & $3.29(1.51)$ & 0.164 & 0.003 & $<0.001$ \\
\hline Public Meetings & $2.68(1.39)$ & 0.098 & 0.111 & 0.394 \\
\hline Social Media & $2.63(1.54)$ & 0.765 & $<0.001$ & $<0.001$ \\
\hline Word of Mouth & $2.77(1.54)$ & 0.048 & 0.032 & 0.005 \\
\hline
\end{tabular}

*Note: Rank 1 = Least preferable and $5=$ most preferable.

twice as likely to acquire information via word-of-mouth (OR 2.206, 95\% CI 1.386-3.512).

\subsection{Respondent awareness}

A significantly higher level of awareness was found among post-intervention respondents with respect to system type $(\mathrm{p}<0$. 001) and DWWTS as potential sources of environmental contamination ( $\mathrm{p}<0.001$ ) (Table 4a). Conversely, pre-intervention respondents were more likely to exhibit an awareness of DWWTS age ( $p$ $=0.003)$ and system influent $(p=0.013)$ (See Table 5.)

No significant mean awareness score difference was found between pre- and post-intervention respondents $(p=0.886)$ (Table $4 \mathrm{~b})$; while this was also the case among homeowners ( $\mathrm{p}=$ $0.550)$, a higher level of awareness $(p=0.022)$ was found among pre-intervention non-homeowners. Further analyses of the postintervention sample population indicates a significant difference with respect to derived awareness score and age $(F(6)=7.980$,

Table 4

(a) Individual components of awareness performance indicator stratified by pre/postintervention respondent status and associated odds ratios; (b) Mean awareness scores stratified by homeownership, and associated statistical test results.

\begin{tabular}{llll}
\hline & $\begin{array}{l}\text { Pre- } \\
\text { Engagement }(\%)\end{array}$ & $\begin{array}{l}\text { Post- } \\
\text { Engagement }(\%)\end{array}$ & $\begin{array}{l}\text { Odds Ratio (Sig } \\
\left.\left(\chi^{2}\right)\right)\end{array}$ \\
\hline 4a. & & & \\
System Type & 53.8 & 70.2 & $2.022(<0.001)$ \\
System Age & 87.8 & 82.4 & $0.649(0.003)$ \\
System Influent & 70.1 & 64.1 & $0.763(0.013)$ \\
$\begin{array}{l}\text { Previous } \\
\quad \text { Inspection }\end{array}$ & 93.0 & 93.0 & $0.997(0.989)$ \\
$\begin{array}{l}\text { Previous } \\
\quad \text { Desludging }\end{array}$ & 90.3 & 89.7 & $0.937(0.720)$ \\
Environmental & 78.0 & & $4.264(<0.001)$ \\
$\quad$ Threat & & 93.8 & \\
4b. & & & Sig $(\mathrm{t})$ \\
$\quad$ Mean Score & Mean Score & 0.886 \\
\hline $\begin{array}{l}\text { Total Population } \\
\text { Homeowners }\end{array}$ & 4.60 & 4.59 & 0.550 \\
Non- & 4.26 & 4.97 & 0.022 \\
$\quad$ Homeowners & & 3.96 & \\
\hline
\end{tabular}

Table 5

Post-intervention system remediation expectancy and DWWTS health threat acknowledgement, stratified by homeownership.

\begin{tabular}{llll}
\hline & $\begin{array}{l}\text { System } \\
\text { Remediation (\%) }\end{array}$ & $\begin{array}{l}\text { General Health } \\
\text { Threat (\%) }\end{array}$ & $\begin{array}{l}\text { Household Health } \\
\text { Threat (\%) }\end{array}$ \\
\hline Total & 20.3 & 92.1 & 83 \\
Homeowners & 22.1 & 93.2 & 85.7 \\
Non-homeowners & 16.5 & 90.1 & 78.1 \\
\hline
\end{tabular}

$\mathrm{p}<0.001$ ); Bonferroni post hoc tests (using the $45-54$ year group as reference group) indicate a lower mean awareness of 1.002 (16.7\%) among 18-24 year olds, and 0.726 (12.1\%) among 25-34 year olds. Respondents who reported receiving relevant information as part of the NIP were associated with a higher level of awareness (5.05 vs. 4.76$)(\mathrm{t}=-2.144, \mathrm{p}=0.033)$, with this association particularly marked among non-homeowners (4.59 vs. 4.05 ).

Overall, $56.6 \%$ of post-intervention respondents reported being aware of how to correctly inspect their domestic treatment system, with gender $(\mathrm{p}=0.024)$, age $(\mathrm{p}=0.002)$ and homeownership $(\mathrm{p}<0$. 001 ) all significantly associated with awareness of inspection procedures. Male respondents were approximately 20\% more likely aware of the inspection process (OR 1.203, 95\% CI 1.020-1.428), while procedural awareness was higher among older respondents. Similarly, receipt of information was associated with awareness of inspection procedures $\left(\chi^{2}(1)=15.868, \mathrm{p}<0.001\right)$ and a significantly increased likelihood of procedural awareness (OR 2.775, 95\% CI 1.664-4.629). Furthermore, an attempt to acquire information was associated with a significantly higher respondent awareness score $(\mathrm{t}=-3.003, \mathrm{p}=0.003)$.

In all, 93.3\% and 90.1\% of homeowners and non-homeowners, respectively, agreed that poorly-maintained DWWTSs constituted a public health threat $(p=0.273)$. There was a high level of acknowledgement of poorly maintained systems as a household health threat; with $86 \%$ of homeowners and $78.1 \%$ of nonhomeowners respectively agreeing $(\mathrm{p}=0.058)$. Interestingly, a significantly higher proportion of respondents with treated domestic water supplies (85.7\%) acknowledged a household health threat than those with untreated supplies $(76.8 \%)\left(\chi^{2}(1)=4.326, p=\right.$ 0.038). 


\subsection{Respondent behaviour}

As shown (Fig. 2), there was a reported increase in desludging frequency during the study period $\left(\chi^{2}(3)=74.594, \mathrm{p}<0.001\right)$. However, a significant shift was noted among non-homeowners, with results indicating a decrease in mitigative/preventative actions (i.e. inspection, monitoring, and desludging) over the study period ( $p=0.001$ ) (Table $6 \mathrm{~b}$ ), with the inspection and monitoring components of "behavioural performance" shown to decline significantly among this sub-population.

A significant relationship was found between respondents' belief that their DWWTS would require remediation and those having previously undertaken desludging $\left(\chi^{2}(1)=13.906, \mathrm{p}<0.0\right.$ $01)$. Respondents who had not previously desludged their domestic system were 1.8 times more likely to believe that remediation would not be necessary (OR 1.826; 95\% CI 1.327, 2.514). Conversely, respondents that reported regular monitoring of their system were 5 times more likely to believe that their system would require remediation ( $\mathrm{OR}$ 5.133; 95\% CI 3.863, 6.820). Postintervention respondents who had previously attempted to acquire relevant information were more likely to have inspected their DWWTS $\left(\chi^{2}(1)=13.264, \mathrm{p}<0.001\right.$; OR 3.061, 95\% CI 1.639, 5.718). Similarly, a higher proportion of respondents who had attempted to acquire information reported previous desludging (31.3\% vs $22.3 \%$ ), although this was not statistically significant at the $95 \%$ level $(p=0.062)$.

\subsection{Respondent attitudes}

Naughton and Hynds (2014) previously developed three distinct "attitudinal clusters", namely, (HQ) comprising respondents exhibiting relatively positive attitudes towards environmental governance and underlying governmental motives (i.e. regulations applied for the good of human health $(\mathrm{H})$ and water quality protection (Q)); (RC) comprising respondents with a more negative attitude towards governance (i.e. regulations applied for revenue generation (R) and/or obligatory compliance (C)); and (M-RQ) representing respondents who were undecided and tended toward case-by-case judgements. An analogous approach was taken with the post-intervention sample to quantify the magnitude of attitudinal change over the course of the NIP (Table 7). A significant attitudinal difference was found between pre- and post-intervention respondents $\left(\chi^{2}(2)=56.986, \mathrm{p}<0.001\right)$; lower proportions of post-intervention respondents were associated with the HQ and M-RQ clusters, with a significantly higher proportion of RC (negative attitude) membership. Neither gender $(p=0.383)$ nor age $(p=$ 0.127 ) were associated with cluster membership, however homeowners were significantly more likely to be members of the RC and M-RQ clusters $\left(\chi^{2}(2)=10.155, \mathrm{p}=0.006\right)$.

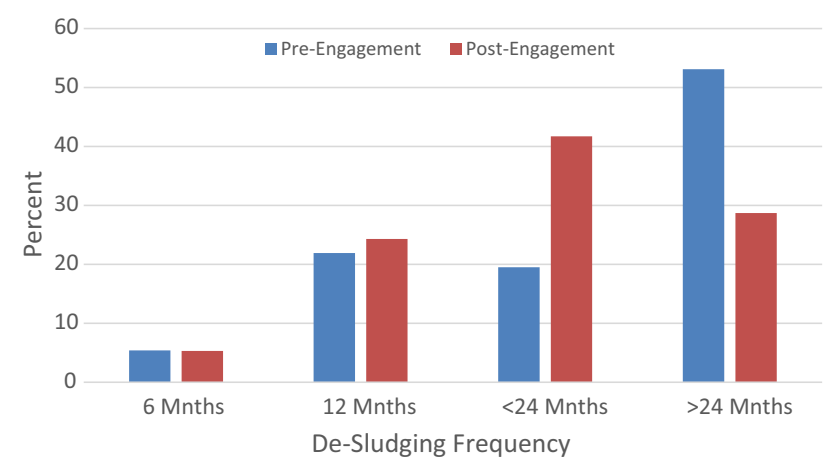

Fig. 2. Reported DWWTS desludging by pre- and post-intervention respondents.

\section{Table 6}

(a) Individual components of behavioural performance indicator stratified by pre/post-intervention respondent status and associated odds ratios; (b) Mean action (behavioural) scores stratified by homeownership, and associated statistical test results.

\begin{tabular}{llll}
\hline Component & $\begin{array}{l}\text { Pre-Intervention } \\
(\%)\end{array}$ & $\begin{array}{l}\text { Post-Intervention } \\
(\%)\end{array}$ & $\begin{array}{l}\text { Odds Ratio } \\
\left(\operatorname{Sig}\left(\chi^{2}\right)\right)\end{array}$ \\
\hline 6a. & & & \\
Inspection & 82.6 & 78.8 & $0.784(0.084)$ \\
Monitoring & 20.6 & 18.9 & $0.899(0.441)$ \\
Desludging & 74.6 & 72.4 & $0.892(0.376)$ \\
6b. & & & Sig (t) \\
\hline Total Population & 1.65 & Mean Score & 0.071 \\
Homeowners & 1.64 & 1.57 & 0.819 \\
Non-Homeowners & 1.67 & 1.65 & 0.001 \\
\hline
\end{tabular}

Table 7

Membership of developed "attitudinal clusters" among pre- and post-intervention survey respondents.

\begin{tabular}{llll}
\hline & HQ (\%) & RC (\%) & M-RQ (\%) \\
& “Positive" Attitude & $\begin{array}{l}\text { “Negative" Attitude } \\
\text { Undecided }\end{array}$ \\
\hline Pre-Intervention & 26.8 & 51.5 & 21.7 \\
Post-Intervention & 18.7 & 72.3 & 9.0 \\
\hline
\end{tabular}

\subsection{Performance indicators}

All three indicators were significantly associated; an increased level of respondent awareness co-occurred with an increased action score $(p<0.001)$. Calculated respondent awareness was associated with cluster membership $(\mathrm{F}(2)=4.887, \mathrm{p}=0.008)$; while mean awareness scores were not significantly different between the "negative" (Mean 4.8) and "positive" (Mean 4.72) clusters, the mean awareness score associated with the "undecided" cluster (Mean 5.02) was significantly higher ("negative" p $=0.025$; "positive" $\mathrm{p}=0.008$ ) than both. Conversely, the lowest mean action score was associated with the "undecided" attitudinal cluster $(F(2)=3.628, p=0.027)$.

\section{Discussion}

This study sought to quantify current ('post-intervention') levels of awareness among Irish DWWTS owners, and establish whether awareness and behaviours have changed over the course of a national engagement campaign. Findings are based upon two unmatched cross-sectional surveys ( $n=1634$ ), with the principal advantage offered by this study being the direct comparison between ex-ante and ex-post awareness, attitudes, and behaviour, via a series of developed indicators.

During the first full year of the inspection regime (July 2013 June 2014), a reporting period during which the postintervention survey was undertaken, 987 household DWWTS inspections were carried out nationwide, $48 \%$ of which failed (EPA, 2015). The most frequently cited reason for inspection failure was a lack of desludging ( $>50 \%)$, while other recurrent factors included ineffective DWWTS operation and/or maintenance, unlicensed or inappropriate discharges (e.g. rainwater, surface drainage), and system leakages (EPA, 2015).

General socio-demographic results from the current study align with previous hazard-related risk awareness and perception studies, with gender (Scolobig et al., 2012), age, and homeownership (Burningham et al., 2008) all associated with respondent 
awareness. Higher levels of awareness among post-intervention respondents concerning DWWTSs as sources of waterborne contaminants, combined with a 2.8 -fold increase in agreement with DWWTS monitoring and inspection (support rose to $80 \%$ from $58.5 \%$ pre-intervention), suggests a degree of cognitive engagement with several issues addressed by the communication campaign. Conversely, behaviours were not found to directly manifest themselves as pro-environmental or protective responses (i.e. a lack of behavioural engagement). Accordingly, the authors conclude that NIP activities were not "engaging", and were simply dissemination of information. Citizen engagement with respect to hydrological (and other) issues requires continual reciprocation of information and, perhaps more importantly, functional interaction between the public and public/policy bodies initiating the engagement scheme (Armstrong, 2013). Conversely, some view the public having engaged by being "passive recipients of information" or by providing their opinion through questionnaires (Rowe and Frewer, 2005), thus citizen engagement itself represents a relatively fluid concept with a wide (or entirely absent) spectrum of characterisation. Indeed, the terminology associated with public communication campaigns, citizen engagement, and participation are frequently used interchangeably, and thus confusion remains regarding the use of terminology. In this case, the campaign (NIP) was not what is generally considered engagement and would probably have benefitted from employing engagement strategies.

A scoping review of the literature and comprised definitions indicates that the primary aim of a public communication campaign is development of behaviour conducive to desirable social outcomes (Coffman, 2002; Atkin and Rice, 2012), in this case, the level of behavioural change resulting from the NIP campaign was found to be limited. While respondents acknowledged contamination risks, other factors would appear to limit precautionary behaviours; previous studies report that factors such as familiarity with a pre-existing risk, voluntariness of exposure combined with (perceived) personal control over a hazard, may modify a threat perceived by a household, thereby reducing their motivation to act (e.g. Griffin and Dunwoody, 2000). Decision-making processes and actions in environmental and human health scenarios are often predicated on prior experiences, interpersonal networks, heuristics and emotions. Previous investigations of household behaviours relating to DWWTSs and private wells have noted low health, environmental literacy levels and negligible stewardship in parallel with risk acceptance (Mankad, 2012; Castleden et al., 2015; Chappells et al., 2015). Nonetheless, there is at least an indication of perceived control or optimistic bias in this study, whereby those respondents associated with treated drinking water supplies were more likely to acknowledge a household health threat than those with untreated supplies, thus suggesting that people with untreated water supplies may be overly confident about the quality of their water.

Study findings indicate a discernible shift towards the negative RC 'attitudinal cluster' (Table 7); while a large proportion of respondents associated with membership of the negative cluster were previously "undecided" (M-RQ), a sizable number have shifted directly from a positive to more negative attitude. Important factors associated with general awareness and behaviour include personal values and/or beliefs and trust (Muro et al., 2012). It is considered likely that proliferation of a more generally negative attitude among study participants captures the recent general decline in public trust in political institutions (O'Sullivan et al., 2014), the experience of austerity associated with recent global financial events (Kinsella, 2012), and ongoing controversy concerning water policy reforms and efforts to introduce water charges in Ireland, (Kelly-Quinn et al. 2014). These declines in public trust necessitate actions by local and national authorities given the relationship between trust and societal adoption of precaution- ary behaviours (Lo et al., 2015). For example, actions for improving public perception towards authorities within the realm of hydrological risk may include free system registration and assessment, free system remediation upon inspection failure, or free connection to a municipal treatment system if preferred. Adoption of mechanisms facilitating active dialogue and potential incentives may reduce householder scepticism and alleviate practical barriers (e.g. financial, accessibility) (Dean et al., 2016).

While findings reveal an increased level of self-reported awareness among those in receipt of information, only 35\% of postintervention respondents reported receiving information without seeking to acquire it; similar to the baseline pre-intervention level. The majority (55\%) of post-intervention respondents who received information adjudged it as being useful, with preferences for sources of information being linked to age. Reported awarenesslevels amongst the younger and associated "non-homeowner" cohorts were found to decline over the study period, thus reflecting an important sub-population (i.e. future custodians) for future demographically-focused outreach and engagement activities.

Those who attempted to acquire information (i.e. information seeking) exhibited higher levels of cognitive awareness, and were more likely to have previously desludged their DWWTS, in line with equivalent precautionary responses found in previous hazard studies (Hynds et al., 2013; Naughton and Hynds, 2014). However, more generally, receipt of information and respondent behaviour were not found to be related. This is particularly worrying given the high reported rates of microbial contamination in rural water-supplies in Ireland (Hynds et al., 2012); albeit, this likely further explains the persistence of this source of transmission. This finding builds on Naughton and Hynds (2014) who identified that unregulated private groundwater users exhibited the lowest awareness of DWWTS as a potential source of aquatic contaminants despite being the group at greatest risk.

"Self-efficacy" is frequently highlighted as an important factor in people's self-protective behaviours (Bubeck et al. 2013). In the current study, those respondents who had previously demonstrated awareness and taken actions (visual inspection, desludging, etc.) were more likely to believe their system would require future remediation in the event of an inspection, contrasting with those never having taken any remedial action; 'out of sight, out of mind' may be one potential explanatory factor (Devitt et al. 2016). As observed by Devitt et al. (2016) in Ireland, the presence of contamination does not always equate to acknowledgement. Absence of sensory cues, cumulative household immunity to disease, protracted time-lag effects, and lack of familiarity with onsite DWWTS and/or private wells may lead householders to incorrectly assume non-existence of contamination and shirk their duties (Paul et al., 2015; Devitt et al., 2016). There is evidently a need to acknowledge the role of experiential and sensory factors in determining household risk perception and behaviour towards DWWTSs in particular and hydrological risks in general (de França Doria, 2010).

At the cohort level, all three derived indicators were significantly associated. With a multitude of differing definitions and terminology frequently ascribed to concepts such as awareness (e.g. knowledge, perception), attitude (e.g. beliefs, values, feelings) and behaviour (action, preparedness, mitigation), it is difficult to accurately compare results with previous studies. Nevertheless, the apparently "circular" pattern of association uncovered in the current study would seem to resonate with the general literature concerning environment (including hazards) and behaviour (e.g. Raaijmakers et al., 2008; Devitt et al., 2016), often incorporating theoretical frameworks that seek to recognise the complexity of factors frequently competing to influence and shape decisions and actions, and similarly the persistence of well-established awareness-action gaps (Mankad, 2012; Castleden et al., 2015) found across elements of this study. 
These contrasting findings provide evidence of the inherent complexity of influencing behaviour in a population characterised by stratification into differing cohorts of awareness, attitude and behaviour. Theoretical perspectives related to public communication assist in understanding the cognitive processes and behavioural determinants that inform information absorption and decision-making. If message content, form and style are appropriately tailored to the attributes, abilities, and interests of different audience types, campaign effectiveness will likely increase (Atkin and Rice, 2012). For example, advancing behavioural change requires a more segmented communication strategy by targeting householders understanding and perception of hydrological risk. Similarly, true "engagement" (as opposed to communication) strategies must involve active dialogue and trust building between policymakers and the population (O'Neill et al. 2016) as campaigns which truly engage members of the public will have a better chance of success. Whilst there are significant challenges associated with uncovering the specific factors inhibiting (and encouraging) behavioural change, an association between public awareness, the perception of hydrological risk (and public health), and environmental "stewardship" is recognised and should be applied. With risks to human health likely to be perceived as more immediate than an environmentally framed risk, a health-framed and demographically focused approach to communications, in line with personal priorities, has been recommended to promote behavioural change in future hydrological awareness raising activities (Devitt et al. 2016).

\section{Conclusion}

Findings from the current study indicate that the NIP risk communication strategy failed to engender a significant change in behaviour among DWWTS users in Ireland. Overall, a low percentage of respondents received or attempted to access information pertaining to DWWTS operation and maintenance, while similar behavioural shortcomings and knowledge gaps were displayed among both pre- and post-intervention respondents. Despite a greater acknowledgement of the contamination risks posed by DWWTSs, a significant portion of post-intervention respondents failed to translate awareness into action; survey results are comparable to findings in other spheres of hydrological/environmental management. To prompt uptake of protective behaviours, this study suggest that organizations communicate information with a variety of audience profiles in mind and acknowledge the value of behavioural and cognitive theories in tailoring messages and media. The clarity and accessibility of technical information is likely a further factor.

DWWTS user risk awareness and stewardship displayed a notable correlation with socio-demographic variables, indicating the importance of age and homeownership; accordingly, demographically focused engagement approaches are recommended. The value-action gap and a decline in public trust, allied with scepticism about regulatory motivations may have contributed to the low level of reported behavioural change and high proportion of respondents exhibiting negative attitudes towards environmental regulation. This suggests a need for implementation of more discursive, face-to-face communication mechanisms to rebuild confidence in environmental management, reinforced by respondents' preferences for 'word-of-mouth' information sources and interpersonal communication. Face-to-face, local communication initiatives have proved effective in previous water risk campaigns and are especially pertinent in rural areas decentralized from political centres of power.

As global hydrological issues persist and likely proliferate due to climate change, cognizance of public disposition toward envi- ronmental risk and self-responsibility is prerequisite to mounting effective campaigns. By exploring awareness, attitudes and behaviours among DWWTS users on a temporal basis, this study offers valuable insights into the underexplored area of hydrological risk communication and identifies several knowledge gaps requiring attention. To foster greater risk awareness and change monitoring and maintenance behaviours among DWWTS users, a communication campaign must be theoretically informed. Incorporation of message framing, risk perception theory, and message tailoring may enable policymakers to influence broader audience types and attain greater responsiveness.

\section{Acknowledgements}

The authors would like to thank all anonymous respondents for taking the time to complete the questionnaires, and several national non-professional interest groups (ESAI, IAH, ICA, NFGWS) for survey distribution. This research received support from the Environmental Protection Agency (Ireland) STRIVE programme (Project Number 2013-W-SS-10). The authors would also like to thank two independent reviewers for their insightful queries, comments, and recommendations which greatly helped improve the manuscript.

\section{References}

Armstrong, E., 2013. The Role of Active Participation and Citizen Engagement in Good Governance. UN Public Administration Programme: Division for Public Administration and Development Management. New York, September 2013.

Atkin, C.K., Rice, R.E., 2012. Theory and Principles of Public Communication Campaigns. In: Rice, R.E., Atkin, C.K. (Eds.), Public Communication Campaigns. 4th Ed. SAGE, Thousand Oaks, CA.

Borchardt, M.A., Bradbury, K.R., Alexander, E.C., Kolberg, R.J., Alexander, S.C., Archer, J.R., Spencer, S.K., 2011. Norovirus outbreak caused by a new septic system in a dolomite aquifer. Ground Water 49 (1), 85-97.

Bubeck, P., Botzen, W., Kreibich, H., Aerts, J., 2013. Detailed insights into the influence of flood-coping appraisals on mitigation behaviour. Global Environ. Change 23, 1327-1338

Burningham, K., Fielding, J., Thrush, D., 2008. 'It'll never happen to me': understanding public awareness of local flood risk. Disasters 32 (2), 216-238.

Castleden, H., Crooks, V.A., van Meerveld, I., 2015. Examining the public health implications of drinking water-related behaviours and perceptions: a face-toface exploratory survey of residents in eight coastal communities in British Columbia and Nova Scotia. Canadian Geographer 59 (2), 111-125.

Chappells, H., Campbell, N., Drage, J., Fernandez, C.V., Parker, L., Dummer, T.J.B. 2015. Understanding the translation of scientific knowledge about arsenic risk exposure among private well water users in Nova Scotia. Sci. Total Environ. 505, 1259-1273.

Coffman, J., 2002. Public Communication Campaign Evaluation: An Environmental Scan of Challenges, Criticisms, Practice, and Opportunities. Harvard Family Research Project, Cambridge, MA.

CSO, 2012. Census 2011 Profile 4: The Roof over our Heads - Housing in Ireland. Central Statistics Office, Cork.

Cussen, N., 2010. Implications of Ground and Surface Water Regulations for Planning Policy and Practice. EPA/DEHLG Water Quality Seminar. Athlone, Co Westmeath, Ireland, April 2010.

Dean, A.J., Lindsay, J., Fielding, K.S., Smith, L.D.G., 2016. Fostering water sensitive citizenship - community profiles of engagement in water-related issues. Environ. Sci. Policy 55, 238-247.

Devitt, C., O'Neill, O., Waldron, R., 2016. Drivers and barriers among households to managing domestic wastewater treatment systems in the Republic of Ireland; implications for risk prevention behaviour. J. Hydrol. 535, 534-546.

EPA (Environmental Protection Agency),, 2013. National Inspection Plan 2013: Domestic Waste Water Treatment Systems. Environmental Protection Agency, Wexford.

EPA (Environmental Protection Agency),, 2015. National inspection plan: domestic waste water treatment systems - a review of the period 1st July 2013-30th June 2014 \& consultation on proposals for 2015-2017. Environmental Protection Agency, Wexford.

European Commission, 2011. Environment: Commission takes Ireland back to court over septic tanks and asks for a fine. European Commission Press Release Database, 19 May

Garvey, P., Carroll, A., McNamara, E., McKeown, P.J., 2016. Verotoxigenic Escherichia coli transmissions in Ireland: a review of notified outbreaks, 2004-2012. Epi. Infection 144 (5), 917-926.

Griffin, R.J., Dunwoody, S., 2000. The relation of communication to risk judgment and preventive behaviour related to lead in tap water. Health Commun. 12 (1), 81-107. 
Howlett, M., Cashore, B., 2009. The dependent variable problem in the study of policy change: understanding policy change as a methodological problem. J. Compar. Policy Anal. 11(1):33-46.

Hynds, P.D., Misstear, B.D., Gill, L.W., 2012. Development of a microbial contamination susceptibility model for private domestic groundwater sources. Water Resour. Res. 48 (12).

Hynds, P.D., Misstear, B.D., Gill, L.W., 2013. Unregulated private wells in the Republic of Ireland: consumer awareness, source susceptibility and protective actions. J. Environ. Manage. 127, 278-288.

Hynds, P.D., Misstear, B.D., Gill, L.W., Murphy, H.M., 2014. Groundwater source contamination mechanisms: Physicochemical profile clustering, risk factor analysis and multivariate modelling. J. Contam. Hydrol. 159, 47-56.

Kelly-Quinn, M., Blacklocke, S., Bruen, M., Earle, R., O’Neill, E., O’Sullivan, J., Purcell, P., 2014. Dublin Ireland - a city addressing challenging water supply, management and governance issues. Ecol. Soc. 19 (4), 10.

Kinsella, S., 2012. Is Ireland really the role model for austerity? Cambridge J. Econ. 36 (1), 223-235.

Lo, A.Y., Xu, B., Chan, F.K.S., Su, R., 2015. Social capital and community preparation for urban flooding in China. Appl. Geogr. 64, 1-11.

Lumley, T., 2013. Package "survey". Available at:http://cran.rproject.org web/packages/survey/survey.pdf

Mankad, A., 2012. Decentralised water systems: emotional influences on resource decision making. Environ. Int. 44, 128-140.

Muro, M., Hrudey, S.E., Jude, S., Heath, L., Pollard, S., 2012. Making it real: what risk managers should know about community engagement. J. Environ. Assess. Policy Manage. 14, 1-21.
Naughton, O., Hynds, P.D., 2014. Public awareness, behaviours and attitudes towards domestic wastewater treatment systems (DWWTS) in the Republic of Ireland. J. Hydrol. 518, 108-119.

ÓhAiseadha, C., Hynds, P.D., O’Dwyer, J., Fallon, U., 2017. Environmental and infrastructural predictors of verotoxigenic E. coli (VTEC) 0157 infection in the Republic of Ireland, 2008-2013. Epidemiol. Infection (In Press).

O'Neill, E., Brereton, F., Shahumyan, H., Clinch, J.P., 2016. The impact of perceived flood exposure on flood-risk perception: the role of distance. Risk Anal. 36 (11), 2158-2186.

O'Sullivan, S., Healy, A.E., Breen, M.J., 2014. Political legitimacy in Ireland during economic crisis: insights from the European Social Survey. Irish Political Stud. 29 (4), 547-572.

Paul, M.P., Rigrod, P., Wingare, S., Borsuk, M.E., 2015. A community-driven intervention in Tuftonboro, New Hampshire, succeeds in altering water testing behaviour. J. Environ. Health. 78 (5), 30-39.

Raaijmakers, R., Krywkow, J., van der Veen, A., 2008. Flood risk perceptions and spatial multi-criteria analysis: an exploratory research for hazard mitigation. Nat. Hazards 46 (3), 307-322.

Rowe, G., Frewer, L.J., 2005. A typology of public engagement mechanisms. Sci. Technol. Hum. Values 30 (2), 251-290.

Scolobig, A., De Marchi, B., Borga, M., 2012. The missing link between flood risk awareness and preparedness: findings from case studies in an Alpine Region. Nat. Hazards 63 (2), 499-520.

Scott, M., Murray, M., 2009. Housing rural communities: connecting rural dwellings to rural development in Ireland. Housing Stud. 24 (6), 755-774. 